\title{
纯有机超分子发光材料的研究进展
}

\author{
严子昂邹雷马骧* \\ (华东理工大学精细化工研究所 结构可控先进功能材料及其制备教育部重点实验室 上海 200237)
}

\begin{abstract}
摘要 纯有机发光材料由于具有低毒性、易制备和应用广泛等特点而被广泛关注. 近年来, 本课题组设计了多种新颖 的、具有可调控多色发光性质的超分子体系. 对于磷光材料的构建来说, 诸如溴和碘的重原子以及氧之类其他具有孤 对电子的杂原子可以起到促进系间窝越(ISC)的作用. 主一客相互作用和聚合等方法也为磷光体提供了刚性环境，以抑 制其非辐射跃迁. 另外, 非共价作用因其具有动态的特性，能对刺激做出响应. 因此，主-客相互作用与疏水作用、 $\pi-\pi$ 堆积以及多氢键作用等非共价作用也被用于根据外界刺激调控磷光或荧光的发射强度和波长, 实现了发光单体本身不 具备的丰富发光性能. 除总结上述进展之外, 还为未来的研究提出了可能的方向, 例如在设计有机磷光材料时, 不仅 要提升其量子产率，也要拓展发射波长范围，以及构建能够对外界刺激进行响应的智能发光材料体系等.
\end{abstract}

关键词＼cjkstart发光材料; 室温磷光; 超分子化学; 刺激响应材料

\section{Recent Advances in Pure Organic Luminescent Supramolecular Materials}

\author{
Yan, Zi'ang Zou, Lei Ma, Xiang* \\ (Key Laboratory for Advanced Materials, Institute of Fine Chemicals, \\ East China University of Science and Technology, Shanghai 200237)
}

\begin{abstract}
Pure organic luminescent supramolecular materials with either phosphorescence or fluorescence emission have become a hot research topic due to their low toxity, facile preparation and wide applications. In recent years, our group has designed several novel luminescent macromolecules, achieving tunable multi-color emission. For the construction of phosphorescent materials, heavy atoms such as bromine and iodine as well as other hetroatoms with lone pair electrons like oxygen were employed to facilitate the intersystem crossing (ISC) process of the luminophores while rigid environments were provided via host-guest interactions and polymerization to restrict molecular motions, which results in reduced nonradiative decay. Moreover, noncovalent interactions are stimuli responsive because of their dynamic nature. Therefore, host-guest interactions, along with other noncovalent interactions including hydrophobic effects, $\pi-\pi$ stacking and multiple hydrogen bonding, were also used for adjusting the intensities and wavelengths of phosphorescence or fluorescence, achieving diverse luminescence properties that the luminophore itself does not possess. This account summarizes the above advances and proposes possible directions for further research, like not only improving quantum yields but also expanding the range of emission wavelength of organic phosphorescent materials and developing luminescent materials that can intelligently respond to external stimuli.
\end{abstract}

Keywords luminescent material; room-temperature phosphorescence; supramolecular material; stimuli responsive materials

\section{Introduction}

Luminescent materials, including phosphorescent and fluorescent materials, have aroused great interests in recent years and have been fruitfully reported in the field of functional materials for their wide applications in bioimaging, ${ }^{[1]}$ optical sensors,${ }^{[2]}$ molecular switches, ${ }^{[3]}$ anti-counterfeiting materials $^{[4]}$ and organic light-emitting diodes (OLEDs) ${ }^{[5]}$
Pure organic luminescent materials have received special attention for their low toxity and easy preparation. ${ }^{[6]}$ These features are especially important for room-temperature phosphorescence (RTP), which traditionally involves noble metals such as platinum and iridium ${ }^{[7]}$ in order to facilitate the intersystem crossing (ISC) process.

In recent years, our group has utilized supramolecular

* Corresponding author. E-mail: maxiang@ecust.edu.cn

Received April 2, 2020; revised May 1, 2020; published online May 7, 2020.

Project supported by the National Natural Science Foundation of China (Nos. 21722603, 21871083).

国家自然科学基金(Nos. 21722603, 21871083)资助项目. 
chemistry in designing phosphorescent and fluorescent materials. For RTP materials, methods such as polymerization were employed to provide rigid environments for bromo- or oxygen-containing phosphors (Figure 1a). In this approach, RTP in amorphous state has been effectively achieved. ${ }^{[8]}$

For multi-color emissive materials, host-guest interactions, hydrophobic effects, multiple hydrogen bonding and $\pi-\pi$ stacking have also been used to adjust the conformation, vibration or electron distribution of luminophores. Since these noncovalent interactions are sensitive to external conditions such as temperature and $\mathrm{pH}$, fluorescent or phosphorescent materials are endowed with stimuli responsive feature by introducing these noncovalent interactions. Furthermore, photochromic diarylethenes (DAEs), spiropyrans (SPs) and azobenzene can reversibly change their chemical structures upon ultraviolet or visible light irradiation, and hence light responsive luminescent materials containing these units have been constructed (Figure 1b). The stimuli responsive materials can emit light of different colors when the external conditions change and white light emission has also been acquired. ${ }^{[9]}$

Besides luminescent materials in solid state and solution, several hydrogels based on noncovalent interactions have also been prepared, many of which have properties such as rapid self-healing and stimuli response, indicating future applications of supramolecular luminescent soft materials. ${ }^{[10]}$

\section{Room-temperature phosphorescence in amorphous state induced by assembling}

Crystallization, which is able to effectively inhibit the nonradiative decay from the excited triplet state to the ground singlet, has become a feasible way of constructing pure organic RTP materials in solid state. ${ }^{[1]}$ Although great advances have been made, crystals still require strict growth conditions and have low processability, highlighting the significance of amorphous RTP materials. To overcome these shortcomings, we have presented several general design strategies to provide rigid environment for phosphors, inhibiting their nonradiative decay. The amorphous materials obtained are characterized with simple preparation and great processability. ${ }^{[12]}$

\subsection{Phosphorescent copolymers with rigid hydrogen bonding matrix}

Polymer matrix proved to be an ideal choice to provide rigid environment for phosphors. Among all kinds of polymers, polyacrylamide stands out because of its rigid hydrogen bonding network. Several phosphorescent acrylamide copolymers were therefore designed and synthesized with simple radical binary copolymerization.

Since heavy atoms can promote the ISC process, three bromo-containing phosphors, which are non-emissive in amorphous state, were copolymerized with acrylamide to give phosphorescence materials of different colors (polyBrBA, poly-BrNp and poly-BrNpA, Figure 2a). The max-

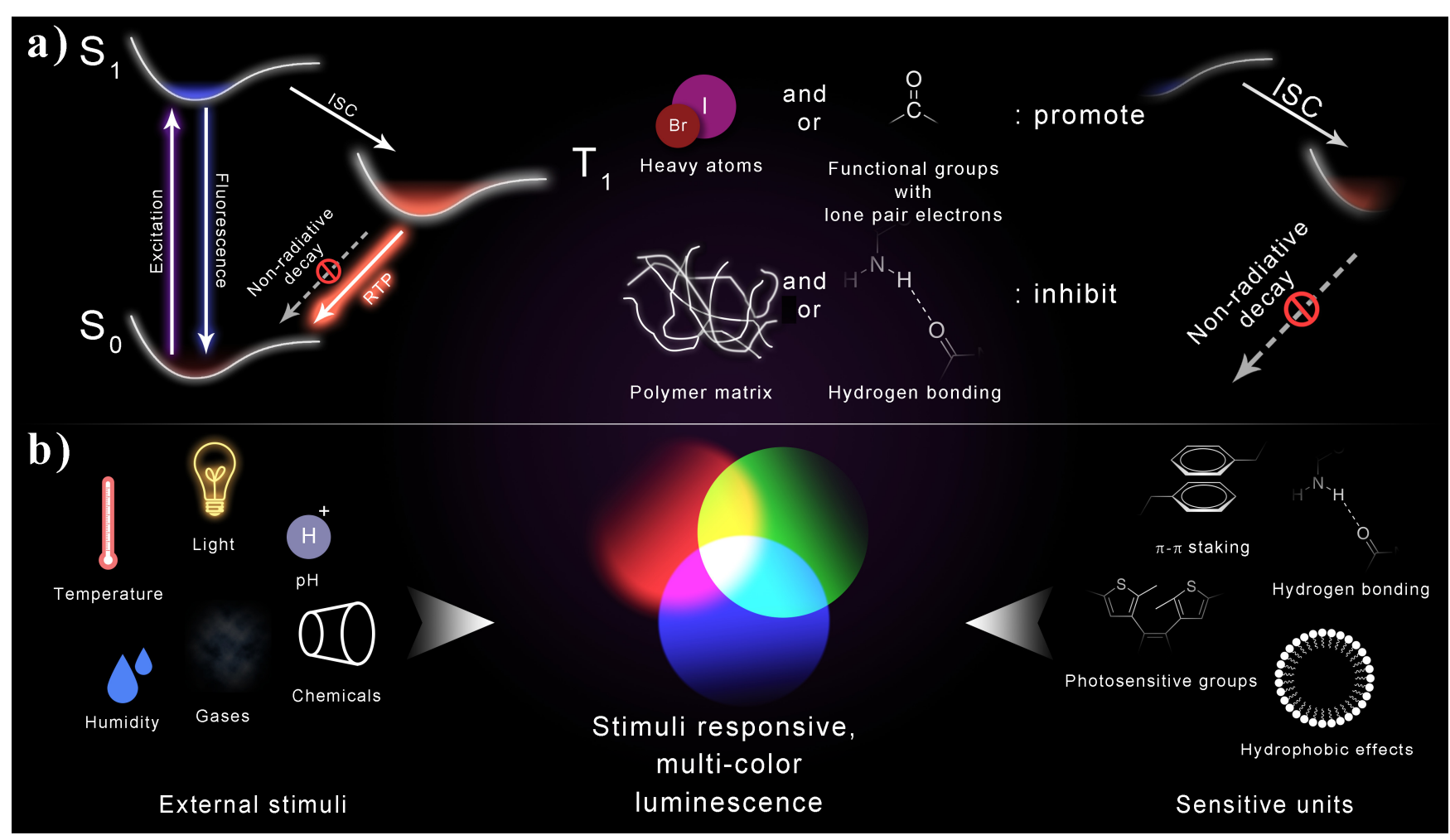

Figure 1 Design strategy of pure organic luminescent materials

(a) Room-temperature phosphorescent materials in amorphous state; (b) stimuli responsive materials with multi-color including white color emission 
imum quantum yield exceeded 10\%. Spin-orbit coupling enhancement by heavy atoms was verified by using the same luminophores but without bromo substitution, which showed no obvious RTP emission. The effect of water was studied by preparing suspension of the polymers in $N, N$ '-dimethylformamide (DMF) $/ \mathrm{H}_{2} \mathrm{O}$ solvent with different volume ratio of water. The results showed that the phosphorescence emissions could be quenched by water, indicating potential applications in encryption ink. Special printer ink was prepared by dissolving one of the phosphorescent polymers in water and the letters were printed with this ink, followed by a drying process. Under $365 \mathrm{~nm}$ UV irradiation, the letters were clearly observed when they were dried and returned dark after the paper was wetted again $^{[8 \mathrm{a}]}$ (Figure 2c). Similar copolymerization strategy was used for 2-bromocarbazole derivatives, emitting blue phosphorescence. ${ }^{[8 f]}$ Furthermore, by using iodo-substituted dipyrromethene boron difluoride (BODIPY) dyes, the emission wavelength was extended to near-infrared region. ${ }^{[10 \mathrm{~b}]}$

(a)

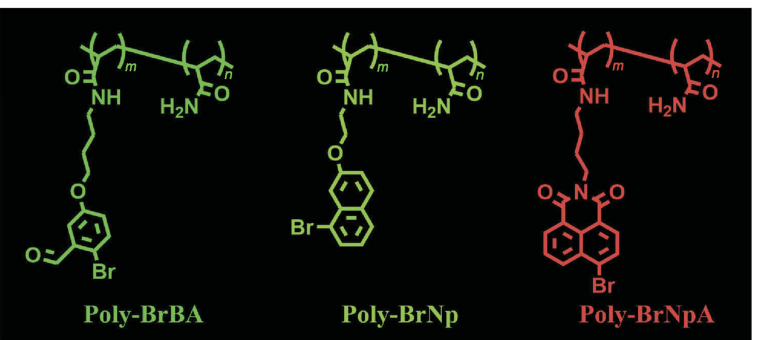

(b)
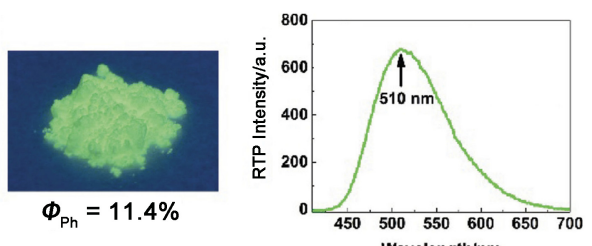

(c) Wavelength/nm

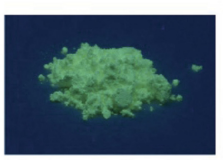

$\Phi_{\mathrm{Ph}}=8.1 \%$
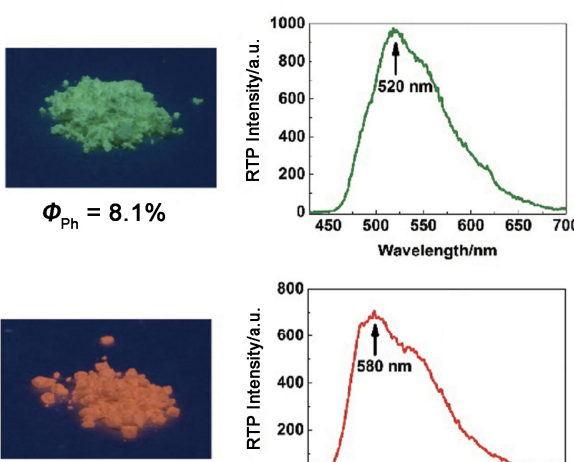

$\Phi_{\mathrm{Ph}}=7.4 \%$
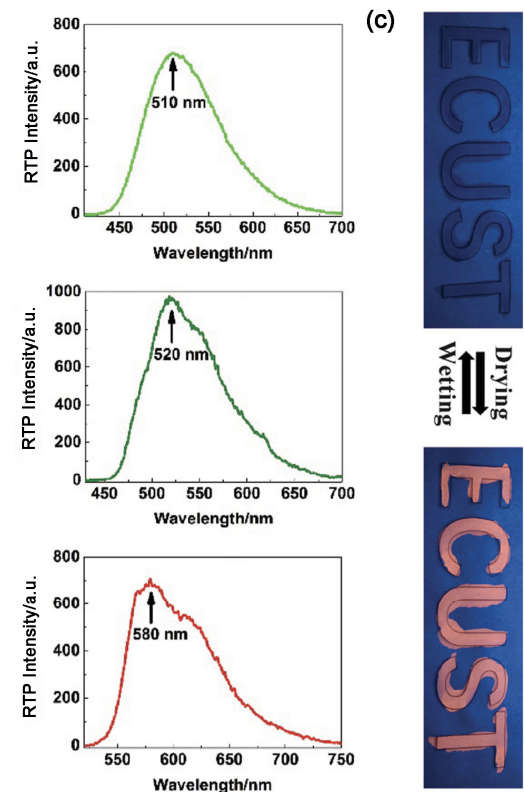

Figure 2 (a) Structures of poly-BrBA, poly-BrNp and poly$\mathrm{BrNpA}$; (b) photographs of the solid powder of the three polymers under 365, 254 and $365 \mathrm{~nm}$ UV light, respectively, and their phosphorescence spectra (excitation wavelength $=350,286$ and $350 \mathrm{~nm}$, respectively); (c) photographs of letters written using aqueous poly-BrNpA solution before and after drying under 365 nm UV light

(a), (b) and (c) were reproduced with permission from Ref. [8a]. Copyright 2016 Wiley-VCH Verlag GmbH \& Co. KGaA
Other functional groups, like oxygen-containing carbon$y l$, can also promote the ISC process. We therefore designed a series of phosphors containing carbonyl groups. Copolymerization of acrylamide with these phosphors was carried out to yield copolymers with ultra-long roomtemperature phosphorescence (URTP) that could last for several seconds and be observed by naked eye. We proved the general applicability of this strategy by preparing ten polymers with URTP (Figures 3a, 3b). The polymer with the longest phosphorescence lifetime (up to $537 \mathrm{~ms}$ ) and a quantum yield of $15 \%$ is $\mathbf{P 3}$ (i.e., the copolymer of compound 3 with acrylamide). ${ }^{[8 b]}$

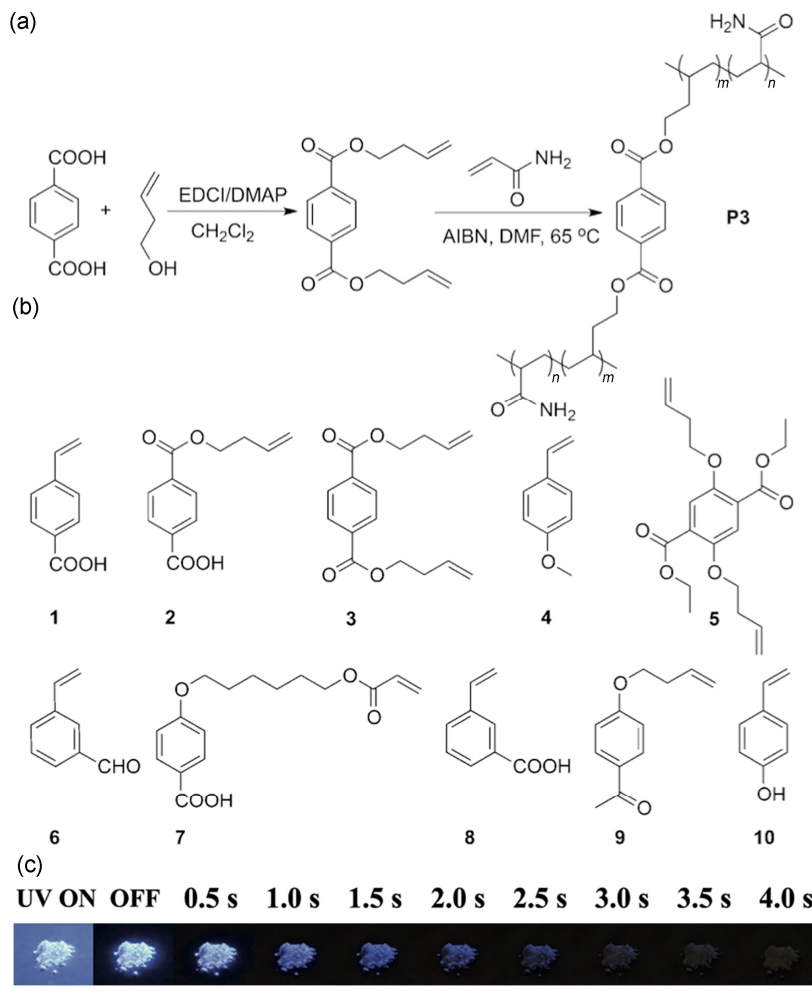

Figure 3 (a) General synthetic route of polymers with URTP, (b) structures of compounds $\mathbf{1} \sim \mathbf{1 0}$, and (c) photographs of P3 powder under and after removal of $254 \mathrm{~nm}$ UV lamp

(a), (b) and (c) were reproduced with permission from Ref. [8b]. Copyright 2018 Wiley-VCH Verlag GmbH \& Co. KGaA]

\subsection{Phosphorescent small molecules with hydrogen bonding}

Besides copolymerizing phosphors with acrylamide, rigidity provided by hydrogen bonding can also be acquired using cyclodextrins (CDs) since CDs can form hydrogen bonds with each other aided by hydroxyl groups. We modified several phosphors with heavy atoms onto $\beta$-CD (Figure $4 \mathrm{a})$. The hydrogen bonding network of $\beta$-CD can effectively suppress the nonradiative relaxion of phosphors and hence improve the phosphorescence quantum yield. ${ }^{[8 \mathrm{~d}]} \mathrm{Just}$ like the case of polymerization, phosphors without heavy atoms were modified onto CDs as well. Several phosphors with carbonyl groups were attached to $\beta$-CD to yield efficient room-temperature phosphorescence (Figure 4b). 
Calculations were implemented to reveal that $\beta$-CD did not affect the frontier molecular orbitals of the phosphors. Given that CDs have no unsaturated groups, it is safe to conclude that all CDs would only provide rigid environment for phosphors but would not affect their electronic properties, providing a general approach to achieve RTP in amorphous state. ${ }^{[8 \mathrm{~d}-8 \mathrm{e}]}$

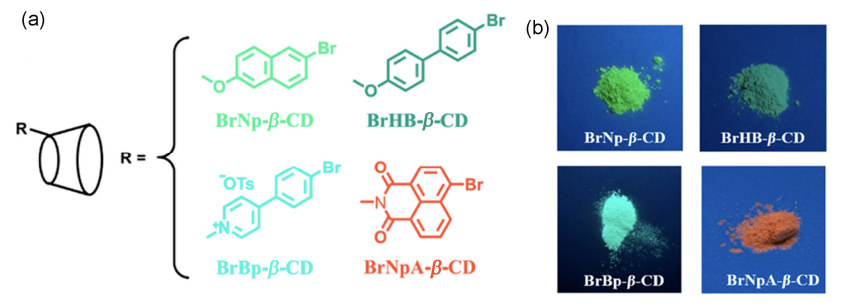

Figure 4 (a) Structures of $\mathrm{BrNp}-\beta-\mathrm{CD}, \mathrm{BrHb}-\beta-\mathrm{CD}, \mathrm{BrBp}-\beta$ $\mathrm{CD}$ and $\mathrm{BrNpA}-\beta-\mathrm{CD}$, and (b) photographs of the solid powder of the four small molecules under 254, 254, 254 and $365 \mathrm{~nm} \mathrm{UV}$ light, respectively

(a) and (b) were reproduced with permission from Ref. [8d]. Copyright 2018 American Chemical Society

X-ray powder diffraction (XRPD) was carried out for all the materials mentioned above, proving their amorphous state without obvious crystal structures, which ensures that they are easy to prepare and process.

\section{Luminescence modulated by external stimuli in solid state and in solution}

\subsection{Fluorescent copolymers with stimuli responsive properties}

With the introduction of dynamic structures, luminescent copolymers are endowed with stimuli responsive characters. Polyacrylamide itself is a responsive structure since its hydrogen bonding network can be broken by water, reducing the rigidity of the matrix. Acrylamide was copolymerized with small amount of tetraphenylethylene (TPE) units to yield TPE-PAM (Figure 5a). The resulting polymer showed strong blue emission which, however, did not come from the well-known aggression-induced emission (AIE) character of TPE, but came from the rigidity provided by the polymer matrix and the hydrogen bonding network since the molar ratio of TPE units was so low in the copolymer that the self-aggregation was minimized. As expected, the copolymer exhibited decreasing emission intensity when it was suspended in $\mathrm{H}_{2} \mathrm{O} / \mathrm{DMF}$ solvent and the volume fraction of water increased from $0 \%$ to $80 \%$. Inspired by this phenomenon, a ternary copolymer TPERhB-PAM (Figure 5a) was prepared, which was composed of TPE units with blue fluorescence and AIE character and $\mathrm{RhB}$ units with red fluorescence but without AIE character, resulting in tunable multi-color emission including a white-light one in $\mathrm{H}_{2} \mathrm{O}$ /DMF solvent under UV irradiation (Figure 5b) ${ }^{[\mathrm{kk}]}$.

Bisthenylethene (BTE) is one of the most promising candidates for photochromic materials and has been used (a)
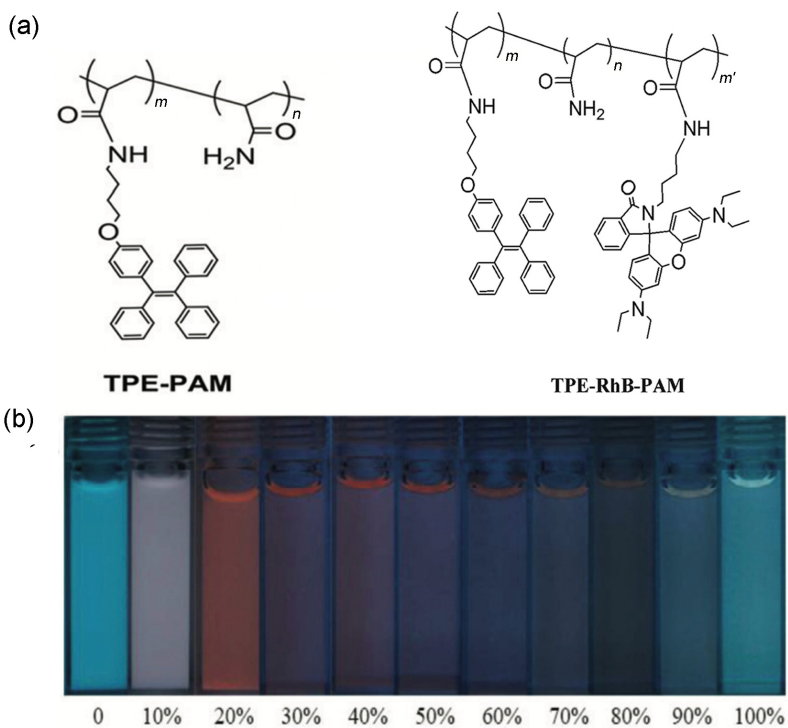

Figure 5 (a) Structures of TPE-PAM and TPE-RhB-PAM, and (b) photographs of TPE-RhB-PAM in $\mathrm{H}_{2} \mathrm{O} / \mathrm{DMF}$ mixed solvent with different volume fraction of water under $365 \mathrm{~nm}$ UV lamp (a) and (b) were reproduced with permission from Ref. [9k]. Copyright 2017 The Royal Society of Chemistry

as another stimuli responsive unit. BTE units undergo reversible changes between the colorless ring-open form and colored ring-closed form via photoisomerization. A ternary copolymer poly(MMA-co-DPC-co-BTE) was therefore synthesized by copolymerizing methyl methacrylate (MMA) with BTE units as photochromic units and DPC units as fluorophores (Figure 6a). The flexible polymer chain does not affect the photoisomerization of BTE units but prevents DPC groups from aggression, avoiding the aggression-caused quenching (ACQ) effect. Upon excitation, the copolymer exhibits bright orange fluorescence at the initial state. The fluorescence can be gradually quenched when the copolymer is continuously irradiated with $365 \mathrm{~nm} \mathrm{UV} \mathrm{lamp,} \mathrm{because} \mathrm{the} \mathrm{ring-closed} \mathrm{form} \mathrm{of}$ BTE generates. The process can be reversed when the polymer is exposed to visible light. Förster Resonance Energy Transfer (FRET) mechanism is the reason for the reversible fluorescence quenching, which is proved with the overlapped absorption spectrum of the ring-closed form of BTE units and the emission spectrum of DPC units. ${ }^{[9 \mathrm{~d}]}$ The phenomenon was observed both in solid film and in solution (Figures 6b, 6c). Another set of fluorophore and photochromic unit, namely TPE and spiropyrans (SP), were also employed, yielding similar results. ${ }^{[\mathrm{i}]}$

\subsection{Phosphorescent copolymers with stimuli re- sponsiveness}

Besides singlet energy transfer, triplet energy transfer between luminophores and photochromic units is also utilized. Spiropyrans have been extensively used in the field of photochromic materials since SPs could convert from closed-loop forms to open-loop forms upon UV irradiation and recover when exposed to visible light (Figure 7a). To achieve photo-responsive luminescence, SP and phosphors 


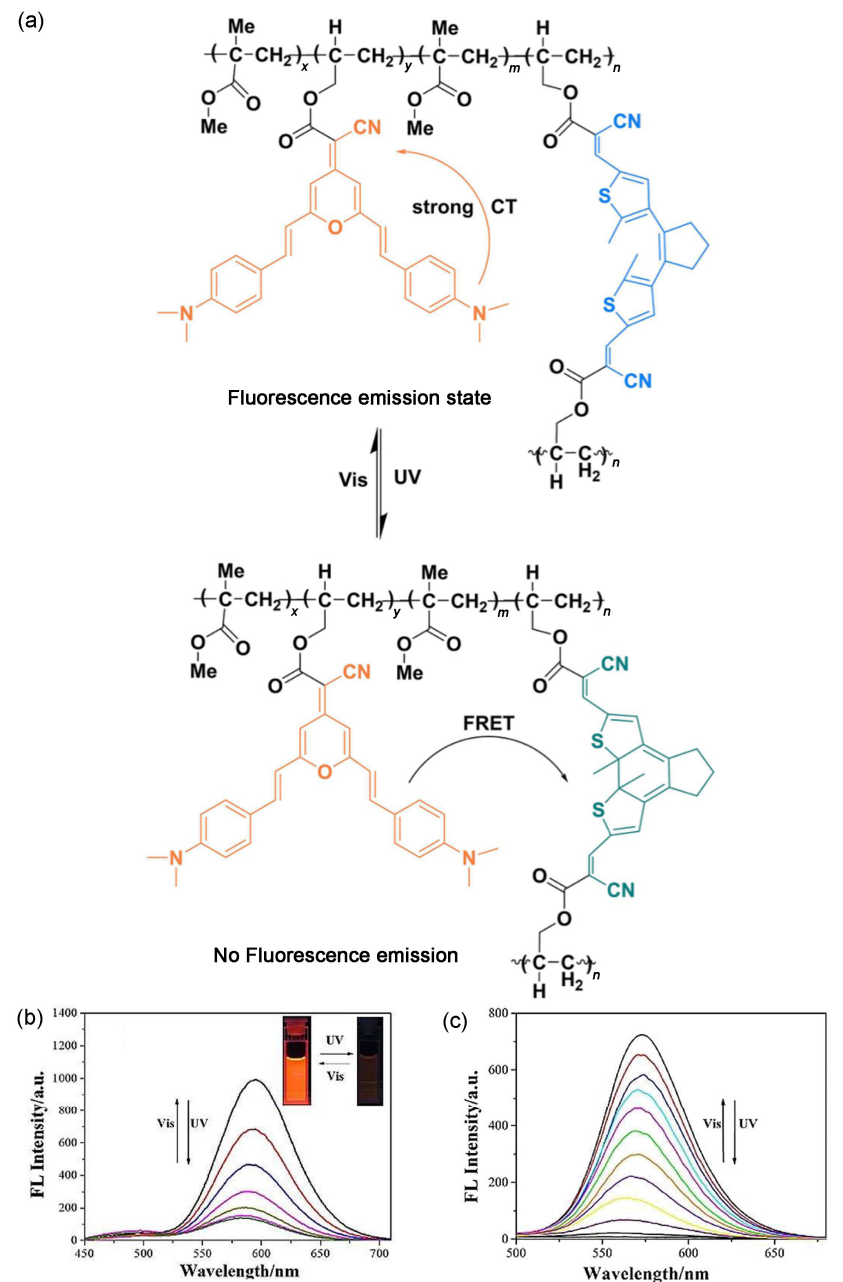

Figure 6 (a) Illustration of photoswitchable fluorescent polymer poly(MMA-co-DPC-co-BTE), and fluorescence emission spectral changes of poly(MMA-co-DPC-co-BTE) in (b) $\mathrm{CH}_{2} \mathrm{Cl}_{2}$ solution and (c) solid state (excitation wavelength $=480 \mathrm{~nm}$ ) (a), (b) and (c) were reproduced with permission from Ref. [9i]. Copyright 2019 Wiley-VCH Verlag GmbH \& Co. KGaA

were copolymerized with acrylamide (Figures $7 \mathrm{~b}, 7 \mathrm{c}, 7 \mathrm{~d}$ ). When exposed to $365 \mathrm{~nm}$ UV irradiation, open-loop SP formed and energy transfer emerged. Both singlet and triplet energy transfer were observed for P1, P2 and P3, resulting in the gradual change of emission color with continues UV irradiation. Taking P1 as an example, the emission color changed from green to yellow to orange under $365 \mathrm{~nm}$ UV irradiation (Figure 7e). Because the RTP emission can be quenched by water and that SPs are temperature-responsive, these polymers also exhibit humidityand temperature-responsive properties. ${ }^{[9 \mathrm{~h}]}$

\subsection{Tunable fluorescence emission via host-guest interactions}

Host-guest interactions, as mentioned above, can endow photoluminescent materials with stimuli responsive character while the interaction between macrocycle and small molecule is an essential part of them. Cucurbit[8]uril $(\mathrm{CB}[8])$ has been commonly used as a host molecule to include luminescent guests, which process is mainly driven (a)

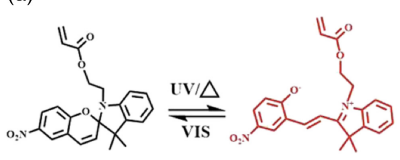

(c)

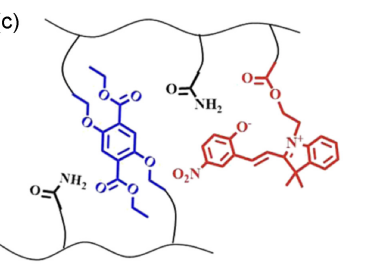

(b)

(d)

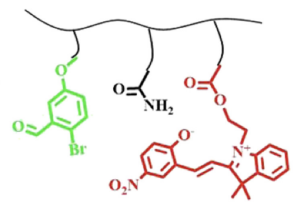

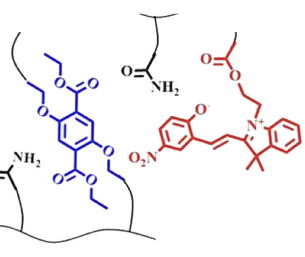

(e) UV ON

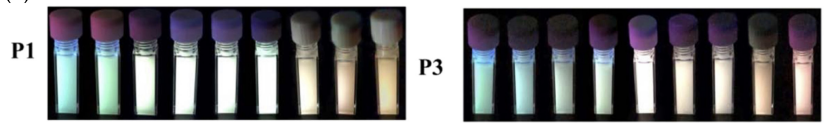

Figure 7 (a) Photosensivity of the SP derivative; Structures of (b) P1, (c) P2 and (d) P3, and (e) photographs showing the emission colors of $\mathbf{P 1}$ and $\mathbf{P 3}$ in DMF under $365 \mathrm{~nm}$ UV radiation and $\mathbf{P} \mathbf{2}$ after the removal of UV lamp

(a) to (e) were reproduced with permission from Ref. [9d]. Copyright 2020 American Chemical Society

by hydrophobic effect as a noncovalent interaction. We elaborated a novel host-guest system based on $\mathrm{CB}[8]$ macrocycle and $N, N^{\prime}$-dimethyl-2,5,-bis(4-pyridinium)thiazolo[5,4- $d]$ thiazole ditosylate (TMV) fluorophore (Figure 8a), which exhibited reversible response to temperature and humidity. TMV can self-assemble into the cavity of $\mathrm{CB}[8]$ in aqueous solution by two binding modes. The molar ratio between the host and the guest can be either $1: 1$ or $1: 2$ (Figure $8 \mathrm{a}$ ). Upon excitation, TMV exhibits blue monomer emission in the former case and greenish-yellow dimer emission in the latter case (Figure 8b), where two TMV molecules stack closely with each other in $\mathrm{CB}[8]$ cavity. When printing $1 / 2 \mathrm{CB}[8] / \mathrm{TMV}$ solutions on substrates such as paper and silica, the emission color can reversibly change from greenish-yellow in wet conditions to blue in dry conditions because of the hydrophobic-effect-driven nature of the host-guest interaction. Moreover, heat can accelerate the free shuttle movement of TMV, achieving temperature-tunable emission. With the elevation of temperature, the blue emission can be enhanced. By mixing $\mathrm{CB}[8] / \mathrm{TMV}$ complex with other temperature-responsive luminescent materials, namely glutathione-modified gold nanoclusters (GSH-AuNCs), a tunable, multicolor, temperature-dependent emitter was fabricated, covering a wide temperature range ${ }^{[9 \mathrm{a}]}$ (Figure 8c).

Molecules with vibration-induced emission character were discovered by our group and attracted continuous attention. ${ }^{[13]} \mathrm{A}$ water-soluble VIE molecule of $N, N^{\prime}$-diphenyldihydrodibenzo[a,c]phenazines derivative (DPAC$A B$, Figure 9a) was chosen as another guest, which could be included into the cavity of the host molecule of bis- $p$-sulfonatocalix[4] arene (BSC4, Figure 9a). By mixing the two substance in water, dual fluorescence was observed (Figure $9 b$ ). The vibration of DPAC-AB along the $\mathrm{N}-\mathrm{N}$ axis could be suppressed via host-guest interaction. 


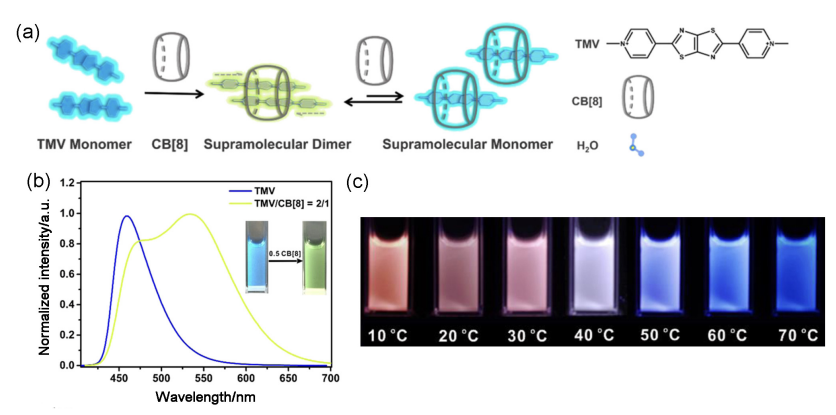

Figure 8 (a) Illustration of CB[8]/TMV system, (b) fluorescence spectra and photographs of TMV and TMV/CB $[8](n: n=$ 2/1) in aqueous solutions under $365 \mathrm{~nm}$ UV lamp, (c) photographs of CB[8]/TMV-GSH-AuNCs solution under $365 \mathrm{~nm} \mathrm{UV}$ lamp

(a) (b) and (c) were reproduced with permission from Ref. [9a]. Copyright 2019 American Chemical Society

Therefore, free state and fixed state of DPAC-AB with different conjugated area and emission properties coexisted in the aqueous solution, resulting in different fluorescence color from orange-red to white to blue (Figure 9c) with the change of the molar ratio between the two forms. Competitive guest like acetylchloride, a neurotransmitter, can affect the inclusion effect between DPAC-AB and BSC4, resulting in recovered fluorescence signal of free-state DPAC-AB, which provides a potential strategy for VIE systems to be applied in areas including responsive biological imagining. ${ }^{[9 c]}$

Combining the concept of host-guest interaction and excitation-dependent emission, a fluorescent molecule BPC (Figure 10a) bearing a pyridinium binaphthol unit (PBN) and a coumarin group with dual sensitivity towards excitation wavelength and the CD host molecule was designed (a)
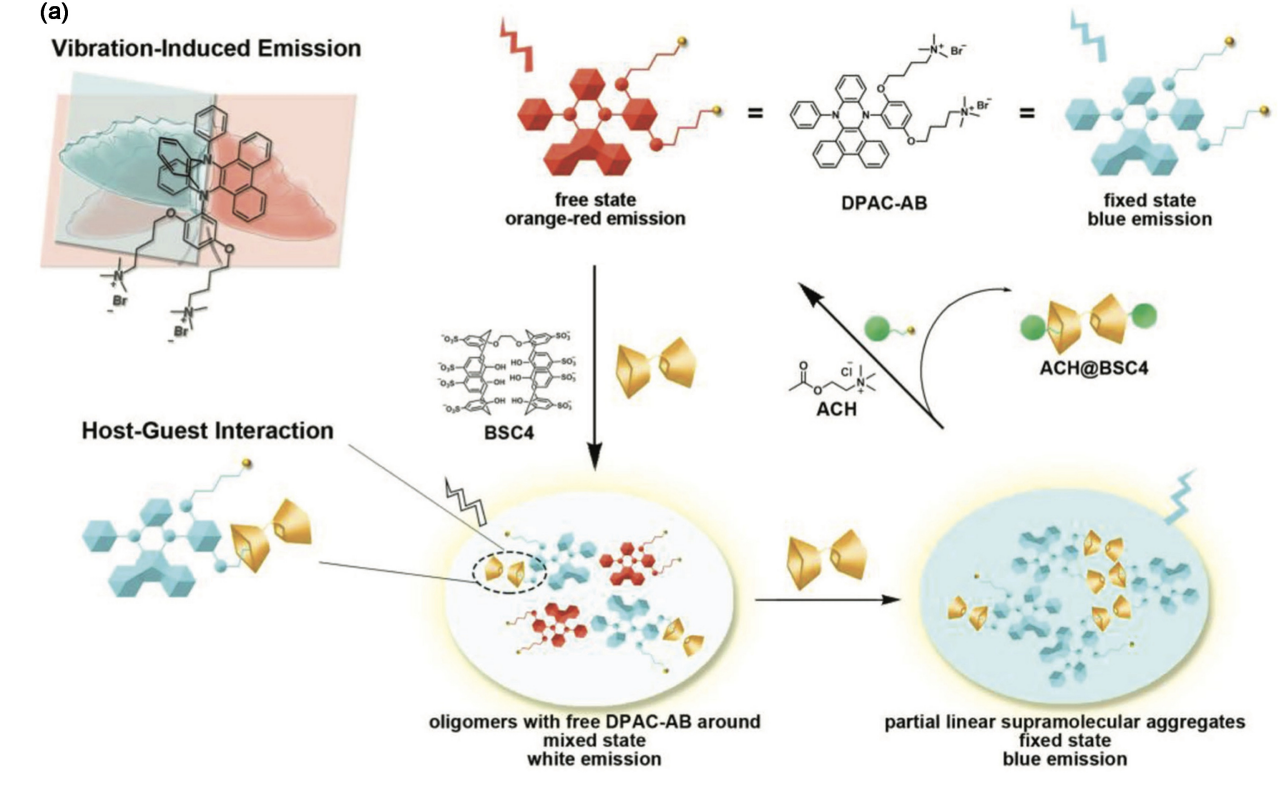
BPC exhibits dual emissions in aqueous solution, which comes from PBN group (blue-green band) and coumarin to pyridinium intramolecular charge-transfer (ICT) emission (red band), respectively. Further investigation shows that the blue emission originates from locally excited PBN, while the green emission is due to excited-state chargetransfer (CT) mechanism, giving the blue-green band excitation-wavelength-dependent character since the relative intensity of the two excited states could change with the excitation wavelength. In addition, the intensity of the red band can be enhanced by adding $\gamma$-CD, as this host molecule can immobilize closely stacked PBN and coumarin groups in the folded state, leading to promoted ICT emission. To sum up, the relative intensity of red $(\mathrm{R})$, green $(\mathrm{G})$, and blue (B) emissions of BPC can be orthogonally modulated based on external conditions, giving multi-color including white emission ${ }^{[9 \mathrm{e}]}$ (Figure 10c).

Substances with AIE characters (AIEgens) have attracted intensive attractions for its distinctive luminescence properties. $^{[14]}$ By grafting TPE units onto pillar[5]arene, an AIE-active host $(\mathrm{H})$ was successfully synthesized (Figure 11). Bithienylethene (BTE) derivative $(\mathrm{G})$ was used as the guest for its photochromic property (Figure 11). The guest contains two cyano-triazole branches and can bind with the host in a $1: 2$ manner in solution (Figure 11). The host-guest complex $(\mathrm{GCH})$ and the free $\mathrm{H}$ both exhibit AIE character in $\mathrm{H}_{2} \mathrm{O}$ /THF solution while the former emits significantly stronger fluorescence than the latter, attributed to the fact that one $\mathrm{G}$ binds with two $\mathrm{H}$, restricting the intramolecular rotation of TPE. Upon $254 \mathrm{~nm}$ UV irradiation, the BTE unit in $\mathrm{G}$ gradually converts from the open form to the closed isomer, transforming $\mathrm{G}$ to $\mathrm{G}-\mathrm{C}$, which
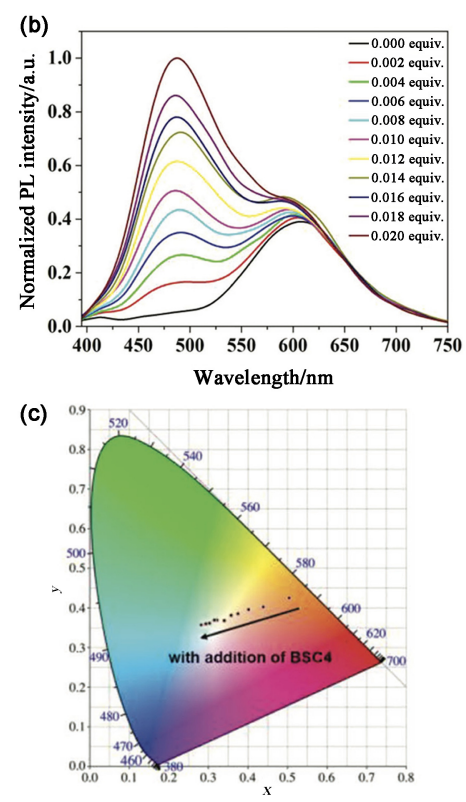

Figure 9 (a) Illustration of DPAC-AB and the corresponding interaction with BSC4, (b) photoluminescence spectra of DPAC-AB $\left(10^{-5}\right.$ $\left.\mathrm{mol} \cdot \mathrm{L}^{-1}\right)$ with different ratio of $\mathrm{BSC} 4$ in $\mathrm{DMSO} / \mathrm{H}_{2} \mathrm{O}(V: V=1: 9)$ mixed solution, and (c) chromaticity coordinate of DPAC-AB solutions

(a) (b) and (c) were reproduced with permission from Ref. [9c]. Copyright 2018 Wiley-VCH Verlag GmbH \& Co. KGaA 
generates a new absorption peak at $516 \mathrm{~nm}$. The FRET process between $\mathrm{H}$ and $\mathrm{G}$ quenches the fluorescence emission of TPE, since the absorption peak of G-C overlaps with the emission peak of $\mathrm{H}$. When being exposed to visible light, the open form of $\mathrm{G}$ regenerates and the fluorescence recovers. The morphology of $\mathrm{G} \subset \mathrm{H}$ in $\mathrm{H}_{2} \mathrm{O} / \mathrm{THF}$ mixed solution can change upon UV irradiation or with the proportion of water, verifying its optical properties. ${ }^{[9 j]}$

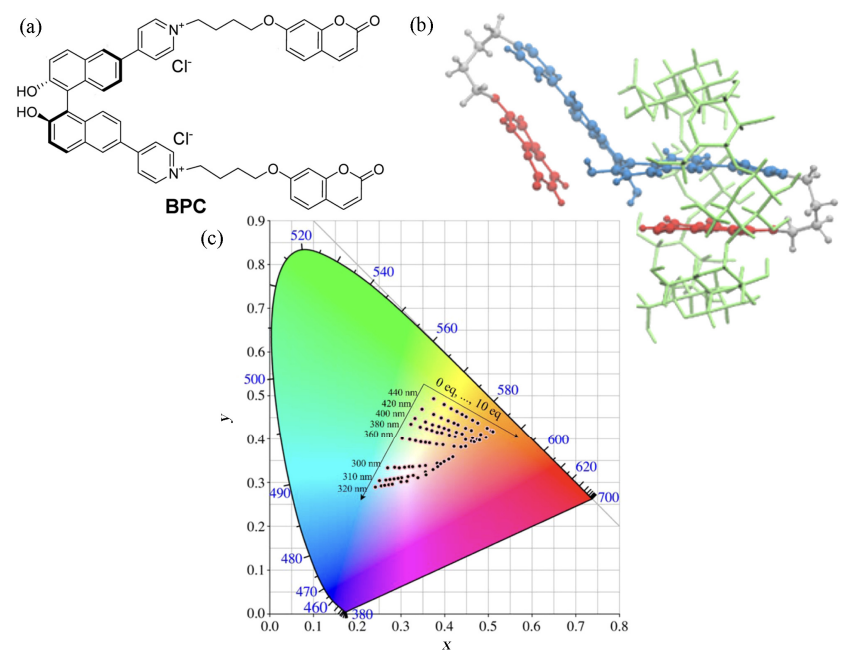

Figure 10 (a) Structure of BPC, (b) simulated structure of the $1: 1$ complex BPCY, and (c) chromaticity of BPC at different excitation wavelength and with different amounts of $\gamma$-CD (a), (b) and (c) were reproduced with permission from Ref. [9e]. Copyright 2016 American Chemical Society

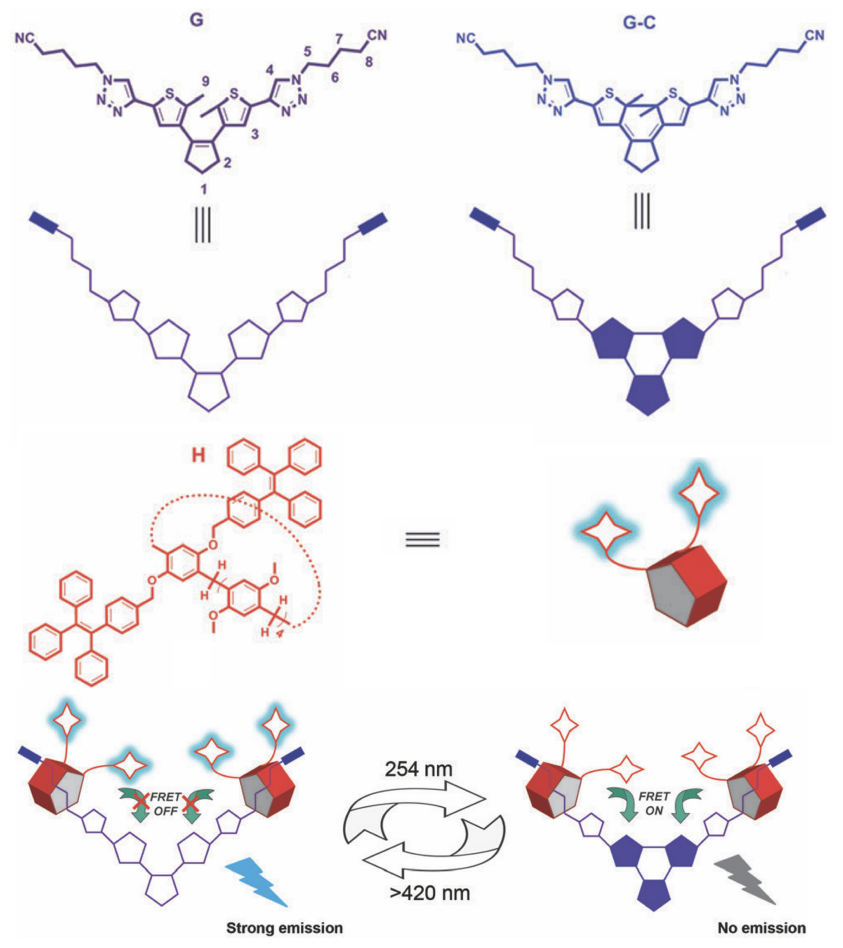

Figure 11 Structures of $\mathbf{H}$ and $\mathbf{G}$, and the illustration of fluorescence switching of the complex

Reproduced with permission from Ref. [9j]. Copyright 2018 The Royal Society of Chemistry

\subsection{Tunable phosphorescence emission via host-} guest interactions

In order to take a step further, we utilized a different fluorescent guest, TBP, along with $\mathrm{CB}[8]$ as the host (Figure 12a). Results showed that the blue fluorescent TBP solution could be modulated by adding different molar ratios of $\mathrm{CB}[8]$. Similar to but not the same with the case mentioned above, $\mathrm{CB}[8]$ allowed two TBP molecules to form a structure-restricted dimer (Figure 12b), exhibiting yellow emission, which was verified with single-crystal $\mathrm{X}$-ray diffraction (XRD). The dimer proved to be a new charge-transfer triplet state upon visible-light excitation (395 nm, Figure 4o), bringing about RTP in aqueous solution, which was rarely reported before. By changing the concentration of $\mathrm{CB}[8]$, the relative emission intensity of the monomer and the dimer changed. The solution therefore exhibited different emission colors including white color (Figure 12c). Adding competitive guests could yield similar result as $\mathrm{TBP} / \mathrm{CB}[8]$ complex disassociates. ${ }^{[9 f]}$

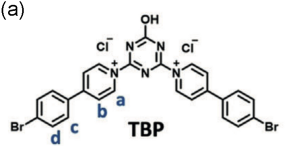

(c)

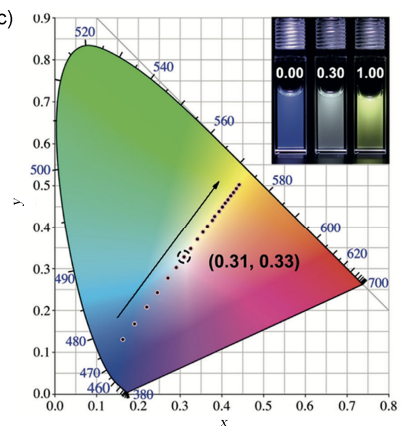

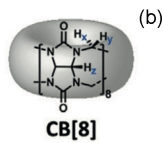
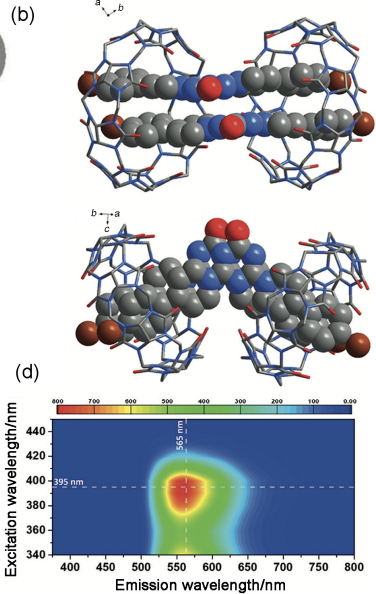

Figure 12 (a) Structures of TBP and $\mathrm{CB}[8]$, (b) side and top views of XRD structure of $(\mathrm{TBP})_{2} \cdot \mathrm{CB}[8]_{2}$, (c) chromaticity coordinate of TBP with different $\mathrm{CB}[8]$ ratios in water in accordance with spectra, and (d) excitation-phosphorescence emission mapping of TBP $(50 \mu \mathrm{mol} / \mathrm{L})$ with 1.0 equiv. of $\mathrm{CB}[8]$

Inset in (c): photographs of TBP with different amounts of $\mathrm{CB}[8]$ in water. (a) to (d) were reproduced with permission from Ref. [9f]. Copyright 2020 Wiley-VCH Verlag GmbH \& Co. KGaA

The assembling behavior of the supramolecular systems mentioned above was confirmed by several methods such as $1 \mathrm{D}$ and $2 \mathrm{D}{ }^{1} \mathrm{H}$ NMR, UV-Vis titration, isothermal calorimetry and/or theoretical calculation.

\section{Conclusions and perspectives}

Pure organic luminescent materials have attracted much attention for their low toxicity and cost. We have utilized supramolecular approach to design diversified phosphorescent and fluorescent materials. Taking advantage of rigidification induced by polymerization, efficient roomtemperature phosphorescent materials in amorphous state have been developed. Several phosphors including bromocontaining ones and heavy-atom free ones have been used 
to construct these polymers. Modification of $\beta$-CD with phosphors also generated RTP with the aid of hydrogen bonding. These pure organic, amorphous materials avoided the disadvantages of toxic metals and crystal growth. Regarding multi-color emitting luminescent materials, several noncovalent interactions as well as photosensitive units have been employed to fabricate color-tuning systems based on a single luminophore, which is sensitive to external stimuli. Multi-color emission including white color emission both in solution and in solid state opens the possibility of applications in various fields, including the next generation of smart materials.

Certainly, much effort is still required to design and develop luminescent materials based on pure organic macromolecules. The performance of amorphous RTP materials remains to be improved. The concept of performance includes not merely quantum yields, but also properties like brightness and the range of emission wavelength. For example, the proportion of phosphors in phosphorescent copolymers is limited because more phosphors would weaken the rigid environment provided by polymer matrix and introduce possible quenching effect. ${ }^{[8 \mathrm{a}-8 \mathrm{c}, 8 \mathrm{f}]}$ This will result in limited absorbance despite a competitive quantum yield. If the quantum yield is at least kept unchanged and the absorbance is enhanced, the overall emission intensity could be improved. Also, amorphous RTP materials with NIR phosphorescence have much room for improvement. As to stimuli responsive luminescent systems, more kinds of responsiveness are expected to be integrated into a single luminophore. In other words, more external stimuli are expected to modulate the emission properties of the luminescent molecules orthogonally. Compared to the all-inone method that involves many luminophores, this one-forall strategy is much more promising both in theory and practice, proving its great potential in the field of stimuli responsive smart materials. Furthermore, such luminescent macromolecules with diverse emission properties pave the way for their application as a substructure in more complex molecular machines, evidenced by a phosphorescent molecular shuttle developed by our group. ${ }^{[15]}$ In summary, by introducing various pure organic luminescent supramolecular materials and putting forward relative perspectives, we believe this account would be a helpful guide for designing and developing emissive materials.

\section{Biographies}

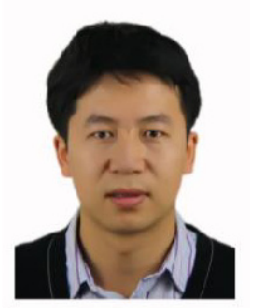

Prof. Ma, Xiang received his bachelor degree from
Tianjin University in 2003 and $\mathrm{PhD}$ from East China University of Science and Technology (ECUST) under the supervision of Prof. Tian, He in 2008. He has been professor of chemistry and fine chemical engineering at ECUST since 2016, where he mainly focuses on organic photo-electro materials based on dyes and stimuli-responsive supramolecules. Prof. Ma is a fellow of the Royal Society of Chemistry (FRSC) and serves as Executive Editor of Dyes and Pigments as well as Member of Colour Index Pigment and Solvent Dyes Technical Board, Society of Dyers and Colourists.

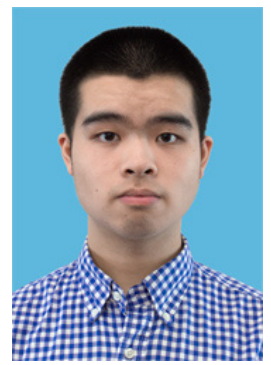

Yan, Zi'ang was born in 1999. Now he is pursuing his bachelor's degree in applied chemistry. His current research interests are focused on pure organic phosphorescent materials.

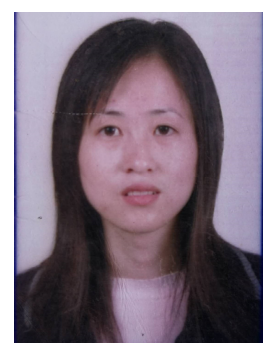

Dr. Zou, Lei received her bachelor from Soochow University in 1997 and PhD from Fudan University under the supervision of Prof. Zhu, Daoben in 2003. She has been working in chemistry at East China University of Science and Technology since 2007, where she mainly focuses on photochromic materials based on dyes.

\section{References}

[1] (a) Gao, R.; Mei, X.; Yan, D.; Liang, R.; Wei, M. Nat. Commun. 2018, 9, 2798.

(b) Miao, Q.; Xie, C.; Zhen, X.; Lyu, Y.; Duan, H.; Liu, X.; Jokerst, J. V.; Pu, K. Nat. Biotechnol. 2017, 35, 1102.

(c) Zhen, X.; Tao, Y.; An, Z.; Chen, P.; Xu, C.; Chen, R.; Huang, W.; Pu, K. Adv. Mater. 2017, 29, 1606665.

[2] (a) Zhou, Y.; Qin, W.; Du, C.; Gao, H.; Zhu, F.; Liang, G. Angew. Chem., Int. Ed. 2019, 131, 12230.

(b) Kim, H. N.; Guo, Z. Q.; Zhu, W. H.; Yoon, J.; Tian, H. Chem. Soc. Rev. 2011, 40, 79.

[3] Ma, X.; Zhang, J.; Cao, J.; Yao, X.; Cao, T.; Gong, Y.; Zhao, C.; Tian, H. Chem. Sci. 2016, 7, 4582.

[4] Jiang, K.; Zhang, L.; Lu, J.; Xu, C.; Cai, C. Angew. Chem., Int. Ed. 2016, $55,7231$.

[5] Lambert, J. S.; Li, H. C.; Wang, Q.; Liu, X. X.; Olivier, J.; Joëlle, R. B.; Liao, L. S.; Jiang, Z. Q.; Cyril, P. Angew Chem., Int. Ed. 2019, 58,3848 . 
[6] (a) Xiong, Q.; Xu, C.; Jiao, N.; Ma, X.; Zhang, Y.; Zhang, S. Chin. Chem. Lett. 2019, 30, 1387.

(b) Qu, G.; Zhang, Y.; Ma, X. Chin. Chem. Lett. 2019, 30, 1809.

(c) Wang, C.; Jiang, T.; Ma, X. Chin. Chem. Lett. 2020, DOI: 10.1016/j.cclet.2020.03.021.

(d) Xu, C.; Xu, L.; Ma, X. Chin. Chem. Lett. 2018, 29, 970.

(e) Wang, S.; Wang, F.; Li, C.; Li, T.; Cao, D.; Ma, X. Sci. China: Chem. 2018, 61, 1301.

(f) Liu, X.; Ma, X. J. East China Univ. Sci. Technol. (Nat. Sci. Ed.) 2019, 45, 517 (in Chinese).

(刘秀军, 马骧, 华东理工大学学报(自然科学版), 2019, 45, 517.) (g) Wang, H.; Shi, H.; Ye, W.; Yao, X.; Wang, Q.; Dong, C.; Jia, W.; Ma, H.; Cai, S.; Huang, K.; Fu, L.; Zhang, Y.; Zhi, J.; Gu, L.; Zhao, Y.; An, Z.; Huang, W. Angew. Chem., Int. Ed. 2019, 58, 18776.

(h) Tian, H.; Zhang, T.; Ma, X.; Wu, H.; Zhu, L.; Zhao, Y. Angew. Chem., Int. Ed. 2019, 59, 11206.

(i) Li, X.; Li, C.; Wang, S.; Dong, H.; Ma, X.; Cao, D. Dyes Pigm. 2017, 142, 481 .

(j) Wang, S.; Xu, M.; Huang, K.; Zhi, J.; Sun, C.; Wang, K.; Zhou, Q.; Gao, L.; Jia, Q.; Shi, H.; An, Z.; Li, P.; Huang, W. Sci. China: Chem. 2019, 63, 316.

(k) He, Z.; Cai, X.; Wang, Z.; Chen, D.; Li, Y.; Zhao, H.; Liu, K.; Cao, Y.; Su, S. J. Sci. China: Chem. 2018, 61, 677.

(1) Ke, K.; Chen, J. X.; Zhang, M.; Wang, K.; Shi, Y. Z.; Lin, H.; Zheng, C. J.; Tao, S. L.; Zhang, X. H. Sci. China: Chem. 2018, 62, 719.

[7] Gan, N.; Shi, H.; An, Z.; Huang, Wei. Adv. Funct. Mater. 2018, 28, 1802657.

[8] (a) Chen, H.; Yao, X.; Ma, X.; Tian, H. Adv. Opt. Mater. 2016, 4, 1397.

(b) Ma, X.; Xu, C.; Wang, J.; Tian, H. Angew. Chem., Int. Ed. 2018, 57, 10854.

(c) Wang, D.; Yan, Z.; Shi, M.; Dai, J.; Chai, Q.; Gui, H.; Zhang, Y.; Ma, X. Adv. Opt. Mater. 2019, 7, 1901277.

(d) Li, D.; Lu, F.; Wang, J.; Hu, W.; Cao, X. M.; Ma, X. J. Am. Chem. Soc. 2018, 1916.

(e) Zhao, C. X.; Jin, Y. H.; Wang, J.; Cao, X.; Ma, X. Chem. Commun. 2019, 55, 5355.

(f) Zhang, T.; Chen, H.; Ma, X.; Tian, H. Ind. Eng. Chem. Res. 2017, 56, 3123

[9] (a) Jiang, T.; Wang, X.; Wang, J.; Hu, G.; Ma, X. ACS Appl. Mater. Interfaces 2019, 11, 14399.

(b) Li, D.; Hu, W.; Wang, J.; Zhang, Q.; Cao, X. M.; Ma, X.; Tian, H. Chem. Sci. 2018, 9, 5709

(c) Wang, J.; Yao, X.; Liu, Y.; Zhou, H.; Chen, W.; Sun, G.; Su, J.; Ma, X.; Tian, H. Adv. Opt. Mater. 2018, 6, 1800074.

(d) Wang S.; Li, T.; Zhang, X.; Ma, L.; Li, P.; Yao, X.; Cao, D.; Ma, X. ChemPhotoChem 2019, 3, 568.

(e) Zhang, Q. W.; Li, D.; Li, X.; Paul, W.; Jasmin, M.; Ma, X.; Ågren, H.; Tian, H. J. Am. Chem. Soc. 2016, 138, 13541. (f) Wang, J.; Huang, Z.; Ma, X.; Tian, H. Angew. Chem., Int. Ed. 2020, 59, 9928.

(g) Zhang, T.; Chen, H.; Ma, X.; Tian, H. Ind. Eng. Chem. Res. 2017, 56, 3123.

(h) Gu, F.; Ding, B.; Ma, X.; Tian, H. Eng. Chem. Res. 2020, 59, 1578.

(i) Gu, F.; Zhang, C.; Ma, X. Macromol. Rapid. Commun. 2019, 40, 1800751.

(j) Ma, L.; Wang, S.; Li, C.; Cao, D.; Li, T.; Ma, X. Chem. Commun. 2018, 54, 2405.

(k) Zhang, C.; Yao, X.; Wang, J.; Ma, X. Polym. Chem. 2017, 8, 4835 .

[10] (a) Chen, H.; Ma, X.; Wu, S.; Tian, H. Angew. Chem., Int. Ed. 2014, $53,14149$.

(b) Zhang, T.; Ma, X.; Tian, H. Chem. Sci. 2020, 11, 482.

[11] Yuan, W.; Shen, X.; Zhao, H.; Lam, J.; Tang, L.; Lu, P.; Wang, C.; Liu, Y.; Wang, Z.; Zheng, Q.; Sun, J.; Ma, Y.; Tang, B. J. Phys. Chem. C 2010, 114, 6090 .

(b) Gong, Y.; Chen, G.; Peng, Q.; Yuan, W.; Xie, Y.; Li, S.; Zhang, Y.; Tang, B. Adv. Mater. 2015, 27, 6195.

(c) Luo, W.; Zhang, Y.; Gong, Y.; Zhou, Q.; Zhang, Y.; Yuan, W. Chin. Chem. Lett. 2018, 29, 1533.

(d) Bian, L. F.; Shi, H. F.; Wang, X.; Ling, K.; Ma, L.; Li, M.; Cheng, Z.; Ma, C.; Cai, S.; Gan, N.; Xu, X.; An, Z.; Huang, W. J. Am. Chem. Soc. 2018, 140, 10734.

(e) Cai, S.; Shi, H.; Li, J.; Gu, L.; Ni, Y.; Cheng, Z.; Wang, S.; Xiong, W. W.; Li, L.; An, Z.; Huang, W. Adv. Mater. 2017, 29, 1701244.

(f) Cai, S.; Shi, H.; Tian, D.; Ma, H.; Cheng, Z.; Wu, Q.; Gu, M.; Huang, L.; An, Z.; Peng, Q.; Huang, W. Adv. Funct. Mater. 2018, 28,1705045 .

(g) Chen, Z.; Shi, H.; Ma, H.; Bian, L.; Wu, Q.; Gu, L.; Cai, S.; Wang, X.; Xiong, W. W.; An, Z.; Huang, W. Angew. Chem., Int. Ed. 2017, 57, 678 .

(h) Li, C.; Tang, X.; Zhang, L.; Li, C.; Liu, Z.; Bo, Z.; Dong, Y.; Tian, Y. H.; Dong, Y.; Tang, B. Adv. Opt. Mater. 2015, 3, 1184

[12] (a) Fang, M. M.; Yang, J.; Li, Z. Chin. J. Polym. Sci. 2019, 37, 383. (b) Gan, N.; Shi, H.; An, Z.; Huang, W. Adv. Funct. Mater. 2018, 28,1802657

[13] Zhang, Z.; Wu, Y. S., Tang, K. C.; Chen, C. L.; Ho, J. W.; Su, J.; Tian, H.; Chou, P. T. J. Am. Chem. Soc. 2015, 137, 8509.

[14] (a) Gu, X.; Kwok, R. T. K.; Lam, J. W. Y.; Tang, B. Biomaterials 2017, $146,115$.

(b) Li, C.; Wu, T.; Hong, C.; Zhang, G.; Liu, S. Angew. Chem., Int. Ed. 2012, 51, 455.

(c) Yang, J.; Ren, Z.; Xie, Z.; Liu, Y.; Wang, C.; Xie, Y.; Peng, Q.; Xu, B.; Tian, W.; Zhang, F.; Chi, Z.; Li, Q.; Li, Z. Angew. Chem., Int. Ed. 2016, 56, 880.

[15] Gong, Y. F.; Chen, H.; Ma, X.; Tian, H. ChemPhysChem 2016, 17, 1934.

(Cheng, F.) 